\title{
Sentido gnoseológico de la memoria según San Agustín
}

La doctrina de la memoria ocupa un lugar tan destacado en el pensamiento de San Agustín que, después de las últimas investigaciones, se nos presenta como la clave para la interpretación de su teología, de su moral y de su gnoseología. Hoy es imposible un conocimiento perfecto de la problemática agustiniana sin una adecuada investigación en este campo de la memoria. Todo el dinamismo del hombre, tanto su vida apetitiva, sus tendencias. como su reflexión, su pensamiento, giran sobre el gozne, oculto unas veces, expreso otras, de la memoria. San Agustín es, sin duda, el primer pensador que elabora una teoría minuciosa, detallada, psicológica y metafísica de la memoria. Es cierto que Platón, Aristóteles, los estoicos desarrollan el tema. Principalmente, la memoria es para Platón, ya se sabe, un supuesto fundamental. Pero será San Agustín quien, tras un cuidadoso examen, la eleve a una categoría metafísica de alcances insospechados. Y lo más original de su teoría ha quedado casi siempre traspapelado bajo el concepto de iluminación, sin que hasta nuestros dias haya sido debidamente revalorizado.

Quizá en Hegel, según alguna interpretación actual haya cobrado la memoria, aunque en otro sentido, una importancia parecida a la que $\mathbf{S}$. Agustín le dio. Para Hegel, ha escrito $\mathrm{H}$.

Marcuse, "el espíritu" supera su forma temporal; niega al tiempo". Pero el "fin" de la historia recaptura su contenido: la fuerza que logra la conquista del tiempo es la memoria (recoleccion). El conocimiento absoluto, dentro del que el espíritu alcanza su verdad, es el espíritu "entrando a su verdadero ser, donde abandona su existencia (ajena) y confía su 
Gestalt a la memoria". Ser ya no es más la dolorosa transcendencia hacia el futuro sino la pacífica recapturación del pasado. La memoria, que ha preservado todo lo que fue, es "la forma interior, y en realidad la más alta, de la sustancia".

El caso es que para San Agustín la memoria significa lo más entrañable y profundo de la naturaleza humana, aquello desde donde esa naturaleza ha de realizarse. $Y$ también aquello hacia lo que esta misma naturaleza ha de dirigirse. Lo inmanente y lo transcendente confluyen en la memoria y únicamente desde ella pueden formularse en la conciencia, no sólo como lo que es así o de otra manera, sino como lo que absolutamente tiene que ser así y no puede ser de otra manera.

Para poder dar explicación de todo el amplio mundo de la memoria, San Agustín tendrá que distinguir dos niveles. El primero, el nivel de la simple constatación de hechos, nivel de la experiencia, de lo empírico. El segundo, el del derecho, el de la necesidad, el del deber-ser. En este último nivel. puramente mental, la vida humana se realiza auténticamente y descubre su verdadero límite, su verdadero sentido, la Verdad misma.

\section{NATURALEZA DE LA MEMORIA}

En la actuación de la memoria observamos, antes de nada, una auplicidad paradójica que determina desde el primer momento su dinámica interna.

Recordar algo es "representar" conscientemente lo que con anterioridad había sido vivenciado por el sujeto. El recuerdo es un acto de la memoria. En cuanto tal, solamente se produce en la medida en que evoco, traigo a la plataforma de mi conciencia presente una cierta "representación". Así, al recordar mi infancia, me la voy haciendo presente en sus distintas etapas, en sus distintas formas y momentos. También me hago presente los lugares por donde transcurrió y las personas con quienes fue paulatinamente desarrollándose. Hay, desde luego, múltiples situaciones de las que ahora no soy capaz de reproducir ni el detalle más insignificante. Permanecen en una oscuridad total. Están ocultas en las zonas más profundas de mi espíritu. Para que 
se transformen en recuerdo expreso he de volverlas a la luz del aquí y ahora en que vivo, a la luz de la actualidad. Pero, a su vez, esta acción que consiste en traer algo de nuevo ante mí, no sólo es una actividad que me pertenece: "Porque no exploramos ahora las regiones del cielo, ni medimos las distancias de los astros, ni buscamos los cimientos de la tierra; soy yo el que recuerdo, yo el alma" ${ }^{1}$, sino que, además, lo que recuerdo, lo evocado corresponde a mi campo vital, al radio de mi propia vida. Sólo así podemos distinguir este peculiar fenómeno psíquico de todos aquellos en los que, como en el imaginar, interviene también una actividad representativa.

Por otra parte, la evocación implica ausencia. No recuerdo lo que en este instante veo, toco y siento. Lo recordaré cuando ya no lo vea, ni toque, ni sienta. Es decir, cuando se haya ocultado en la retaguardia del alma. Mas esta ausencia no ha de ser absoluta, (La ausencia se refiere a la carencia del objeto como estímulo y de la representación sensible). Caso de ser absoluta la ausencia ya nunca podría ser recordada. El recuerdo es, en consecuencia, una ausencia "presente" de una presencia "ausente".

Esta propiedad es fácil de verificar: Supongamos que alguien quiere traernos a la memoria algo de lo que nos hemos olvidado. Nos irá proponiendo diversas cosas para intentar sugerirnos lo que no somos capaces de evocar. Pero no acabamos de recordar lo que deseamos. Sin embargo nos damos cuenta de que aquello que intentamos recordar no es exactamente lo mismo que nos sugieren. No se trata, en consecuencia, de un olvido completo. El mismo discernimiento entre lo buscado y lo propuesto forma parte ya de un cierto recuerdo ${ }^{2}$, es decir, de una cierta presencia, de una presencia oculta, escondida, "ausente", que se hará "presente" al ser evocada.

Y lo mismo sucede en el reconocimiento del recuerdo. Es lo que nos "ocurre cuando vemos alguna cosa y reconocemos ciertamente que la hemos visto alguna vez y aseguramos que la conocemos; nos esforzamos por recordar dónde, cuándo, cómo y con quién ha llegado a nuestra noticia. ¿Se trata de una persona? Buscamos también dónde la hemos

1. Conf. $\mathrm{X}, 16,25, \mathrm{PL} 32,789$.

2. Solit. II, 20,34, PL 32, 902 . 
conocido; y cuando ella nos lo recuerda, de repente, todo nos vuelve a la memoria como una luz, y sin ningún esfuerzo todo lo reproducimos" ${ }^{3}$.

Pero quizá haya algún aspecto, puede pensarse, en el que no se cumpla esta ley. Trátase, pongamos por caso, de la presencia que implicaría el recuerdo del olvido. Porque también me acuerdo de haberme olvidado muchas veces y en múltiples ocasiones. Mas, si el olvido es privación de memoria “¿cómo está presente en la memoria para acordarme de él, siendo así que estando presente no puedo recordarle? No obstante, si es cierto que lo que recordamos lo retenemos en la memoria, y que, si no recordásemos el olvido, de ningún modo podríamos, al oír su nombre, saber lo que por él se significa, síguese que la memoria retiene el olvido. Luego está presente para que no olvidemos la cosa que olvidamos cuando se presenta" ".

Acaso se diga que lo que retenemos es la imagen del olvido, no el olvido mismo, a la manera como retenemos las imágenes de las cosas que han impresionado nuestros sentidos, y por medio de ellas las recordamos. Pero en este caso volvemos a la misma dificultad, ya que, para que una imagen se grabe, es preciso que previamente esté presente la cosa misma de la que obtenemos la imagen. Y, si el olvido está presente en el recuerdo por su imagen es preciso que con anterioridad el olvido haya estado por sí mismo presente. "Mas cuando estaba presente, ¿cómo esculpía en la memoria su imagen, siendo así que el olvido borra con su presencia lo ya delineado? $\mathrm{Y}$, sin embargo, de cualquier modo que ello sea -aunque este modo sea incomprensible e inefable-, yo estoy cierto que recuerdo el olvido mismo con que se sepulta lo que recordamos" ${ }^{5}$. Luego, no nos queda otra solución, si admitimos que se da un recuerdo del olvido, que suponer su presencia en el sujeto para que efectivamente pueda ser recordado.

Observando la cuestión desde otra perspectiva puede hacérsenos comprensible la solución del problema. La verdad es que todo recuerdo directamente procurado, intentado, es una búsqueda. Y esta búsqueda llega a su cumplimien-

3. Id Id.

4. Conf. $X, 16,24$, PL 32. 789

5. Conf $X, 16,25, \mathrm{PL} 32,789-790$. 
to cuando conseguimos la representación consciente de lo buscado. Esta representación consciente implica la presencia de lo representado. Gracias a ella somos capaces, por otra parte, de identificar la realidad concreta como aquello que responde adecuadamente a las exigencias subjetivas en este campo. Por eso, toda desaparición en el olvido no puede ser una desaparición total. $Y$ el olvido mismo no es un borrarse absoluto, sino más bien un ocultarse. "No se puede decir -concluye San Agustín- que nos olvidamos totalmente, puesto que nos acordamos al menos de habernos olvidado y de ningún modo podríamos buscar lo perdido que absolutamente hemos olvidado" ".

Este aspecto de la memoria abre la dimensión del inconsciente y su influencia en el desarrollo posterior de la personalidad. Si el olvido no significa desaparición total, y, sin embargo, representa una retirada de la conciencia presente, es que existe una forma de conservación previa a la conciencia, existe el inconsciente. San Agustín habrá expresado una idea afortunada que alcanzará su plena expresión en la psicología de hoy. "Sería imposible - se ha escrito- tener presente y abarcar en cada momento, en claras representaciones, el conjunto de nuestro pasado anímico, de todo nuestro saber, de todas nuestras experiencias, vivencias afectivas $y$ valores a que hemos aspirado alguna vez. Es manifiestamente una forma de economia el hecho de que nuestro vivenciar esté organizado de tal modo que lo que hemos sentido, pensado, aprendido, querido y experimentado desde nuestra primera infancia se hunda en una región profunda del inconsciente y sólo una parte mínima de nuestro pasado sea consciente, esto es se halla presente en las representaciones del recuerdo" "

La tesis agustiniana tiene, no obstante, una extensión mayor de la que aquí se le da a la memoria en cuanto memoria experiencial. La memoria en San Agustín mantiene esta misma naturaleza aun en aquellas funciones que trascienden toda experiencia. Porque se referirá no sólo al pasado como pretérito, sino también al presente en tanto que realmente vivenciado o susceptible de ser vivenciado. Esta será también la razón de su diferencia con la teoría platónica.

6. Conf. X, 19, 28, PL 32, 791 .

7. LERSCH, Philipp: La estructura de la personalidad, trad. esp. Ramón Sarro, Ed. Scientia, Barcelona, 1966, p. 29. 
Los términos con que Platón describe en el Banquete la presencia del objeto amado son muy parecidos a los que utiliza San Agustín para expresar la presencia de ese mismo objeto y la presencia del recuerdo. El amor, para Platón, se encuentra en el término medio entre la sabiduría y la ignorancia. Ni es sabiduría total, ni es ignorancia total. Y esta ignorancia, que no es un no saber radical, adelanta aquella sabiduría con cuyo logro conseguirá satisfacer su necesidad. Si añadimos la teoría general del conocimiento como recuerdo, fácil será ir determinando el proceso ascensional del hombre, de modo que le sea posible acceder a la Idea en sí. A pesar de todo, Platón necesitará recurrir para explicar el punto de partida inicial a una experiencia previa, a una vida anterior, supuesto que no tiene cabida en la doctrina agustiniana. Por eso San Agustín necesita detenerse mucho más en el análisis del fenómeno de la memoria como puro dato y como función.

\section{LA MEMORIA SENSIBLE}

Mediante la memoria somos capaces, en primer lugar, de revivir, de reproducir las sensaciones y percepciones que en otro tiempo tuvimos, a la vez que las situamos como pasadas. La evocación de lo sentido y percibido supone además su conservación. Y la conservación implica, a su vez, que previamente hayan sido fijadas.

En la memoria están ocultas, de modo distinto y por sus distintos géneros, todas las cosas que impresionaron al hombre a través de sus sentidos: "la luz, los colores y las formas de los cuerpos, por la vista; por el oído, toda clase de sonidos; y todos los olores por el olfato; y todos los sabores por el gusto; y por el sentido del tacto, lo duro y lo blando, 10 caliente y lo frío, lo suave y lo áspero. lo pesado y lo ligero, ya sea extrínseco, ya intrínseco al cuerpo. Todas estas cosas recibe, para recordarlas cuando fuere menester y volver sobre ellas, el gran receptáculo de la memoria y no se qué secretos e inefables senos suyos. Todas estas cosas entran en ella, cada una por su propio sentido, siendo almacenadas alli" 8 .

8. Conf. $X, 8,13, \mathrm{PL} 32,784$. 
Pero no ha de pensarse que lo que fijo y conservo en la memoria son las cosas sentidas, sino sus imágenes. Por eso me es posible, cuando estoy en silencio y a oscuras, representarme, si quiero, los colores, y distinguir el blanco del negro y todos los demás, "sin que me salgan al encuentro los sonidos, ni me perturbe lo que, extraido por los ojos, entonces considero, a pesar de que los sonidos estén allí y, como colocados aparte, permanezcan latentes" 9 .

Gran admiración le produce a San Agustín esta capacidad y esta función de la memoria: "Viajan los hombres por admirar la altura de los montes, y las ingentes olas del mar, y las anchurosas corrientes de los rios, y la inmensidad del océano, y el giro de los astros, y se olvidan de sí mismos, ni se admiran de que todas estas cosas, que al nombrarlas no las veo con los ojos, no podría nombrarlas si interiormente no viese en mi memoria los montes, y las olas, y los ríos, y los astros, percibidos ocularmente, y el océano, sólo creído, con dimensiones tan grandes como si las viese fuera. $\mathrm{Y}$, sin embargo, no es que haya absorbido tales cosas al verlas con los ojos del cuerpo, ni que ellas se hallen dentro de mí, sino sus imágenes. Lo único que sé es por qué sentido del cuerpo he recibido la impresión de cada una de ellas" ${ }^{10}$.

Gracias a la memoria sensible, por lo tanto, puede el hombre despegarse de la particularidad física de las realidades concretas y caminar acompañado de sus imágenes y representaciones. Puede progresar y hacer factible el aprendizaje y la orientación personal en el mundo. No necesita estar constantemente ante las cosas para conocer sus formas elementales, sensibles. Las adquiere en un primer contacto objetivo y con ellas va engrosando poco a poco el campo de su experiencia hasta conseguir los datos precisos para montar el proceso mediante el cual va a desarrollar su propia naturaleza. Cada sentido. siente en la medida en que los estímulos externos actúan sobre él. La memoria permite al hombre reproducir las sensaciones, to percibido, en ausencia de esos mismos estímulos.

Esta visión representativa que se realiza en la intimidad del sujeto merced a la memoria es, desde luego, una ope-

9. Id. Id.

10. Conf. X, 8, 15, PL 32, 785. 
ración compleja. Exige la permanencia de la semejanza del objeto visto, y la formación de la imagen reproductora. "Una cosa es -escribe San Agustín- el recuerdo con permanencia en la memoria, aun cuando se piense en otra realidad, y otra la imagen que evoca el recuerdo al regresar a nuestra memoria y encontrarnos allí con la misma imagen. Porque de no estar alli es tan completo el olvido, que el recuerdo sería imposible ${ }^{11}$.

La razón de esta diferencia es fácilmente comprensible: Si la imagen reproductora, es decir, la imagen expresa, fuese absolutamente idéntica a la imagen impresa, cuando conseguimos una nueva representación, al desaparecer aquélla, debería desaparecer ésta. Sin embargo el antiguo recuerdo perdura en la memoria aun cuando no sea evocado. Prueba de ello es que en algún tiempo futuro somos capaces de reproducirlo nuevamente descubriendo en cada representación distinta su coincidencia con el mismo recuerdo ${ }^{12}$. Esta diferencia hace que debamos suponẹ en el alma una capacidad interior, capacidad de visión interior, que, al ser informada por la semejanza objetiva del recuerdo, se actualiza en verdadera visión, en verdadera representación. Efecto éste que para llevarse a cabo exige, a su vez, una participación activa del sujeto, expresada por la intervención de la voluntad, ya que, de lo contrario parece que aquella actualización no llegaría a cumplirse. "Y así -explica San Agustín- como la voluntad en el mundo exterior aplicaba el sentido a informar al objeto corpóreo $\mathrm{y}$, una vez informado, lo unia, así aquí hace volver sobre la memoria la mirada del alma que recuerda, para que, del recuerdo que aquella retiene, ésta se forme y surja en el pensamiento una visión semejante". La necesidad de la voluntad dedúcese, por otra parte de la importancia que la atención tiene en los procesos de fijación. Cuando camino con la atención puesta en algún pensamiento no veo, ni puedo recordar, el paisaje ni las particularidades del lugar por donde paso ${ }^{13}$.

La distinción entre "el recuerdo oculto en la memoria" y lo que en "el pensamiento se reproduce" nos permite precisar con mayor rigor la diferencia entre memoria e ima-

11. De Trinit. $X I, 3,6$, PL 42, 988-989.

12. Id. Id.

13. Id. Id. De Trinit. $X I, 8,15$, PL 42, 995-996. 
ginación. San Agustín describe esta diferencia en un párrafo extraordinario: "Un sol recuerdo, pues, en realidad, uno he visto; pero si me place, puedo imaginar dos, tres, cuantos quiera, y esta múltiple visión de mi pensamiento es informada por la memoria, que recuerda uno solo. $Y$ lo recuerdo como lo vi; porque si lo recuerdo mayor o menor, ya no recuerdo el que vi, y, por consiguiente, no lo recuerdo. $Y$ pues lo recuerdo, 10 recuerdo con sus dimensiones; no obstante, puedo a voluntad imaginar este sol mayor o menor; y así lo recuerdo como lo he visto y lo imagino como me place, en movimiento o en reposo; viene de donde se me antoja y se dirige a donde yo quiero. Me lo puedo imaginar cuadrado, aunque mi memoria 10 recuerde redondo; del color que desee, aunque es cierto que jamás he visto un sol verde, y, por consiguiente, no lo recuerdo. $\mathrm{Y}$ como hago con el astro del día, puedo hacer con otra cosa cualquiera" ${ }^{14}$.

La memoria se caracteriza por su fidelidad al dato objetivo tal como ha sido recibido. Lo único que realiza es despojarlo de su aspecto inmediato, físico, y de su concreción temporal. Mediante la imaginación caminamos más allá de lo realmente dado. Podemos representarnos lo nunca visto e incluso transformar la realidad.

La imaginación, sin embargo, no puede actuar sin la memoria. Es más, la memoria es la medida de la imaginación. $\mathrm{Y}$ esto en un sentido más radical del que ahora podemos suponer. Pensemos en nuestra actitud ante una narración extraordinaria. A medida que vamos escuchándola, vamos siguiendo con la imaginación todas sus vicisitudes. No parece que participe la memoria. El mundo que me represento es un mundo fabuloso suscitado por las palabras que escucho. No obstante, la intervención de la memoria es evidente. De ninguna manera podría seguir la narración si no recordara, al menos, el sentido de las palabras que escucho. "Si alguien, por ejemplo, me dice: "El monte está limpio de boscaje y poblado de olivos", habla con uno que recuerda y conoce las imágenes de los montes, de los bosques y de los olivos; si los ha olvidado, ignora cuanto se le dice y no puede pensar en dicha narración. Así, pues, todo el que piense en los objetos corpóreos, ora se los imagine, ora los escuche,

14. De Trinit. $\mathrm{XI}, 8,13$, PL 42, 994-995. 
ora lea sucesos pretéritos, ora vaticinios del porvenir, recurra a su memoria y encontrará allí la medida y el modo de cuantas formas su pensamiento contempla" ${ }^{15}$.

La memoria sensible es, en consecuencia, un intermediario necesario en nuestra relación con el mundo. Ninguna realidad concreta podemos imaginar ni pensar sin su participación. Las cosas particulares para ser pensadas han de ser previamente sentidas y recordadas. El proceso es sencillo: "El sentido recibe la imagen del cuerpo; la memoria del sentido y de la memoria, la mirada del pensamiento... Querer apartar la mirada del alma - concluye San Agustíndel recuerdo de la memoria equivale a no pensar" ${ }^{16}$.

\section{MEMORIA AFECTIVA}

En la memoria retengo ciertamente las imágenes sensibles de las cosas. Todo cuanto ha sido percibido puede ser conservado por la memoria. Pero el mundo humano es mucho más amplio que el mundo de las percepciones. No nos limitamos a conocer la realidad, a constatar las cosas, sino que además tendemos hacia el objeto conocido deseándolo o rechazándolo. $Y$ estas tendencias representan para el hombre los cauces por los que se va a desarrollar su personalidad. Mediante ellas el diálogo con el mundo se reviste de una sonoridad especial y las relaciones con las cosas repercuten en lo más profundo del alma provocando estados afectivos múltipes: alegrías, tristezas, amores, odios, esperanzas y desesperaciones... También este nuevo aspecto es confiado a la memoria y por la memoria transmitido. La vida amplía así su horizonte. Gracias a esta pervivencia deja de ser pura sucesión de acontecimientos para convertirse en historia y biografía. Cualquier rotura en la línea de su trayectoria, rotura de la memoria, hace saltar la vida misma transformándose en ese fuego de artificio que serían los sentimientos humanos sin posible relación consigo mismos y con el núcleo fundamental del yo.

"En la memoria me encuentro conmigo mismo y me acuerdo de mí y de lo que hice, y en qué tiempo y en qué lugar, y de qué modo y cómo estaba afectado cuando lo hacía" ${ }^{17}$.

\footnotetext{
15. De Trinit. $X I, 8,14, \mathrm{PL} 42,995$.

16. De Trinit. XI, 8, 15, PL $42,996$.

17. Conf. $X, 8,14$, PL 32,785 .
} 
Todo bloqueo, toda selección, todo alejamiento de los estados afectivos, de lo que hice y de cómo lo hice, supone un bloqueo, selección, alejamiento y mutilación de la memoria y de mí mismo.

Pero el modo de permanecer en la memoria las "afecciones" anímicas, los sentimientos, las experiencias individuales e íntimas es distinto del modo de permanecer las sensaciones y las percepciones. Desde luego, así como en las sensaciones no eran las cosas mismas las que retenía, sino sus imágenes, tampoco aquí son los sentimientos mismos, tal como existieron en el alma en el momento en que los padeció, los que retengo. De hecho, estando alegre puedo recordar la tristeza pasada. $\mathrm{Y}$ al recordar aquella tristeza no por eso dejo de estar alegre. $Y$, de la misma manera, estando triste recuerdo mi alegría, y no temiendo nada recuerdo haber temido alguna vez ${ }^{18}$. La dificultad para entender esto, sin embargo, - dificultad que no se daba en el caso de las imágenes sensibles, ya que allí lo recordado era distinto del que recordaba-, consiste en que la memoria es parte del alma (cum animus sit etiam ipsa memoria) y las alegrías o tristezas pasadas son también alegrías y tristezas del alma. "¿En qué consiste, por consiguiente, que, cuando recuerdo alegre mi pasada tristeza, mi alma siente alegría y $\mathrm{mi}$ memoria tristeza, estando mi alma alegre por la alegría que hay en ella, sin que esté triste la memoria por la tristeza que hay en ella?" 19 .

Ciertamente recuerdo la alegría, la tristeza, el miedo, el deseo pasado. Si no lo recordase no entendería lo que con sus nombres se significa, ni podría hablar sobre ello, ni comprender a quienes me dicen las características que le corresponden. Mas, ¿es la alegría misma la que retengo cuando recuerdo la alegría? ¿Podría ser la imagen de la alegría lo que conservo? Pero la alegría no es susceptible de ser imaginada. No es tantas veces mayor que otra cosa, ni es colorada, dura, blanda, áspera o suave. $Y$ cuando utilizo estos calificativos para referirme a ella, me doy cuenta de que realizo una transposición metafórica, no una designación propia. Su presencia, concluye San Agustín, ha de ser nocio-

18. Conf. $\mathrm{X}, 14,21, \mathrm{PL} 32,788$.

19. Id. Id. 
nal. Lo que retengo es la noción de la alegría, encomendada a la memoria por el alma misma cuando la sintió como experiencia propia. $Y$ con este término: noción, notación, se significa solamente un modo peculiar de permanencia mediante el cual se constata la modificación sufrida por el alma al sentirse afectada, constatación retenida, conservada por la memoria, y desde la memoria evocada. "Vedme aqui -resume San Agustín- en los campos y antros e innumerables cavernas de mi memoria, llenas innumerablemente de géneros innumerables de cosas, ya por sus imágenes, como las de todos los cuerpos; ya por presencia, como las de las artes; ya por no sé qué nociones o notaciones, como las de los afectos del alma, las cuales, aunque el alma no las padezca, las tiene la memoria, por estar en el alma cuanto está en la memoria" ${ }^{20}$.

Lo importante de esta memoria afectiva es que mediante ella mantengo algo de mí mismo, algo del alma, las afecciones, alteraciones, estados, que a lo largo de la existencia se han ido sucediendo. Las imágenes de las cosas sensibles, cuya misión es remitirnos a la realidad del mundo, relacionan al hombre con algo que no es él mismo, con algo distinto del sujeto. Son las cosas las que evocamos a través de ellas. El ser humano puede sentirse más o menos comprometido en este proceso relacional. Las afecciones anímicas recordadas, sin embargo, nos traen a nosotros mismos algo de nosotros mismos. El hombre se mantiene unido en ellas a su pasado. Es él mismo, mediante su memoria, el que se recuerda. Por eso tiene ante sí una relación constante de total compromiso. A San Agustín no le interesan, de momento, (tampoco podía en aquella época llegar a un análisis completo), las repercusiones que este compromiso y que el pasado afectivo puedan tener en el desarrollo integral de la persona. Ni le preocupan los bloqueos que la memoria lleve a cabo sobre la racionalidad, o sobre la satisfacción de las tendencias, ni los que éstas desarrollen, a su vez, sobre la memoria, o las transformaciones a que puedan dar lugar. Quizá convenga señalar que los resultados de estas intervenciones no alcanzarán su plena vigencia hasta el psicoanálisis. Lo que San Agustín intenta destacar ahora es, en primer término, el hecho de la conservación en la memoria de

20. Conf. X, 17, 26, col. 790 . 
las affectiones animi. Hecho que se muestra con facilidad con sólo mirar a nuestra experiencia y comprobar cómo efectivamente recordamos nuestros deseos, alegrias, miedos $\mathrm{y}$ tristezas pasadas. Además, porque sólo podemos entender y discernir el sentido de los términos con los que las designamos si previamente las recordamos. En segundo lugar, investiga San Agustín el modo de encontrarse esas afecciones en la memoria. Es ésta una cuestión ardua y problemática. Podemos afirmar, desde luego, que no se encuentran en la memoria del mismo mođo que están en el alma cuando las padece. Recuerdo, en efecto, mi alegría pasada sin que por eso me sienta alegre en estos momentos. $\mathrm{Y}$, sin embargo, continúa siendo cierto que recuerdo mi alegría, o mis tristezas pasadas. Lo cual quiere decir que no han desaparecido totalmente. Las tiene la memoria, dirá San Agustín, sicut sese habet vis memoriae. Conserva la memoria las nociones de la alegría y de la tristeza mismas, sin que hayan sido recibidas por ningún sentido corporal, "sino que la misma alma, como escribe San Agustín en el capítulo antes citado, sintiéndolas por la experiencia de sus pasiones, las encomendó a la memoria, o bien esta misma, sin haberle sido encomendadas, las retuvo para sí". (No hay que olvidar este sentido de espontáneidad que acaba de destacar San Agustín). Conviene señalar, por otra parte, que en la terminología agustiniana han comenzado a aparecer expresiones propias de la memoria profunda. Me refiero, en concreto, a la palabra noción, que después utilizará preferentemente para expresar el modo de presencia de la verdad. $Y$, desde este primer momento, va a tener el significado preciso que en los análisis posteriores mantendrá, puesto que se utiliza como una cierta constatación de la realidad misma, es decir, de la tristeza o alegría afectivas que en un momento determinado acontecieron en mi espíritu. Quizá ésta sea la razón por la que San Agustín coloca el estudio de la memoria afectiva entre la memoria sensible y la profunda. Pero antes hay que presentar todavía, como perteneciente a la memoria sensible, el tema de la temporalidad.

\section{MEMORIA, TIEMPO Y DURACION}

Vivir es realizarse temporalmente. El hombre no es algo fijo, terminado, inmutable. Esencialmente consiste en ir des- 
cubriéndose, haciéndose, siendo. $Y$ no es que carezca de naturaleza, sino que por naturaleza tiende al futuro para ser. Decir que camina abierto al porvenir es más que una metáfora. Caminar es dirigirse hacia un lugar $u$ otro. $Y$ aquello hacia lo que camina el hombre es, forzosamente, hacia su propia realización. Por eso mismo ha de estar el hombre "abierto" al ser, sobre todo, al ser que caminando conseguirá.

Diferenciar este carácter sucesivo de la vida humana equivale a dotarla de una dimensión temporal. Pero este tiempo vital es irreductible a un simple esquema de ordenación. Los hechos psíquicos, como los hechos físicos, pueden ser clasificados según un antes y un después. Así afirmó: ayer tuve la alegría de encontrarme con un amigo y ayer nevó en la montaña. Ambos fenómenos ocurrieron realmente en el pasado. El pasado anímico, sin embargo, no es un pasado absoluto. Es decir, no es un pasado que, como tal, ha dejado de existir, sin más. De alguna manera se conserva en el presente. $\mathrm{Y}$ el hombre es no sólo lo que actualmente está siendo, sino también lo que a lo largo de su existir ha sido. Nada de cuanto hemos dicho, pensado, deseado, querido, practicado, ha desaparecido totalmente. El pasado nos acompaña como el fruto de nuestra vida personal. Gracias a esta reserva temporal podemos ahora practicar mil operaciones distintas sin tener que comenzar constantemente ese difícil aprendizaje del vivir diario.

A su vez, este pasado retenido, este pasado presente, permite al hombre avanzar hacia el futuro adelantándolo. Vivir es también proyectar. $Y$ todo proyecto implica un hacer presentes los acontecimientos, los sucesos que han de ocurrir. Cuando pienso en mis ocupaciones de mañana estoy reduciendo a hoy el mañana. Incluso en aquellos modos de comportamiento en los que no actúa la reflexión consciente se da una anticipación del futuro. Todas nuestras tendencias, inclinaciones, apetitos, germinan en el campo de la experiencia y se dirigen al porvenir, al futuro. Este porvenir, este futuro, en cuanto objetos de la tendencia se hacen presentes en el alma con la aparición misma de la tendencia. "De este mismo tesoro (del pasado) —escribe San Agustínsalen las semejanzas tan diversas unas de otras, bien experimentadas, bien creídas en virtud de las experimentadas, 
las cuales, cotejándolas con las pasadas, infiero de ellas acciones futuras, acontecimientos y esperanzas, todo lo cual lo pienso como presente" 21 .

El presente anímico, por lo tanto, es una tensión, mejor, una distensión entre el pasado y el futuro. En él se dan cita los distintos momentos de la vida y su confluencia dilata el ámbito humano enriqueciéndolo con las experiencias pretéritas y con las experiencias posibles. Por eso el presente psíquico no es un hiato discontinuo, sino una línea de incidencia. Desde esta perspectiva, la vida humana, lo más profundo y propio de la vida humana, no es en el tiempo, considerado éste como simple sucesión o como esquema de medida del movimiento, sino que es el tiempo. La vida, constitutivamente, es tiempo, es, podemos decir, historia, en cuanto la historia se caracteriza primordialmente por la posibilidad de permanencia de los acontecimientos pasados. De ahí que el tiempo y la historia tengan un ritmo vital: Crecen, disminuyen, aumentan, progresan, se detienen, se alargan o se acortan con la vida misma. $Y$ todo ello significa que la vida psíquica es memoria, ya que sólo la memoria hace posible la temporalidad como presencia.

Para analizar este fenómeno en toda su profundidad hemos de comenzar por un estudio del tiempo como sucesión.

$Y$ lo primero que a este respecto tenemos que decir es que la nota más destacada de este tiempo nos viene ofrecida por la "fluencia", "pasar", el "dejar de ser". Desde luego, si nada pasase no habría tiempo pasado. La misma expresión tiempo pasado lleva consigo el pasar de algo. $\mathrm{Y}$ lo mismo podemos afirmar del tiempo futuro, ya que si nada llegase a ser tampoco podríamos hablar de tiempo futuro. Pero a estos dos tiempos no les conviene propiamente el ser. Porque el pasado, como pasado, ha dejado de ser, y el futuro, en cuanto futuro, todavía no es. De idéntico modo el presente, para ser tiempo, "es necesario que pase a ser pretérito. Pues, si el presente fuese siempre presente y no pasase a ser pretérito, ya no sería tiempo, sino eternidad". De esta manera el tiempo es llegar a ser para dejar de ser, un

21. Conf. $X, 8,14$, col. 785 . 
llegar a ser que consiste en dejar de ser para ser... Non vere dicamus tempus esse, nisi quia tendit non esse ${ }^{22}$.

Nada hay en la sucesión temporal, en cuanto sucesión, que permanezca. $Y$ por ello la idea de una sucesión como totalidad, como síntesis, no responderá al tiempo real, sino que será un artificio de la razón. En esto se funda la diferencia entre tiempo y eternidad. Eternidad es lo que permanece, lo inmutable. "Tus años - comenta San Agustín refiriéndose a la eternidad divina- ni van ni vienen, al contrario de estos nuestros que van y vienen, para que todos sean. Tus años existen todos juntos, porque existen; ni son excluidos los que van por los que vienen, porque no pasan; mas los nuestros todos llegan a ser cuando ninguno de ellos exista ya. Tus años son un día, y tu día no es un cada día, sino un hoy, porque tu hoy no cede el paso al mañana ni sucede al día de ayer. Tu hoy es la eternidad" ${ }^{23}$.

Las expresiones corrientes de la lengua: "tiempo largo", "tiempo breve", por lo tanto, referidas al pasado o al futuro, carecen de sentido, considerado el tiempo como sucesión. Porque "llamamos tiempo pasado largo, por ejemplo, a cien años antes de ahora, y de igual modo tiempo futuro largo a cien años después; tiempo pretérito breve, si decimos... hace diez días, y tiempo futuro breve, si dentro de diez días. Pero ¿cómo puede ser largo o breve lo que no es? Porque el pretérito ya no es, y el futuro todavía no es" ${ }^{24}$.

Quizá convenga, entonces, decir no que es largo el tiempo pasado o el tiempo futuro, sino que fue largo el pretérito, o que será largo el futuro. Pero todavía en este caso cabe preguntar: ¿fue largo cuando era ya pasado o tal vez cuando era aún presente? Cuando era ya pasado, no podía ser largo, porque en cuanto pasado habia dejado de existir. Luego sólo podemos decir que fue largo siendo presente, ya que siendo presente es cuando existía y cuando únicamente podía ser largo ${ }^{25}$.

Tenemos, en consecuencia, que sólo el presente puede ser largo o breve. Mas, ¿en verdad puede ser largo el tiempo presente? Pues si del tiempo presente tomamos una medida cualquiera, siempre que podamos distinguir partes más

\footnotetext{
22. Conf. $X I, 14,17$, col. 816 .

23. Conf. XI, 13, 16, col. 815 .

24. Conf. XI, 15, 18, col. 816 .

25. In Ps. 76,8 y 38,7, PL 36,976 y $418-419$.
} 
simples, ya estamos diferenciando unas como pasadas y otras como presentes. Por lo tanto, sólo ha de considerarse como presente aquel tiempo "que se pueda concebir como indivisible en partes, por pequeñísimas que éstas sean". Este tiempo presente "vuela tan rápidamente del futuro al pasado, que no se detiene un instante siquiera. Porque, si se detuviese, podría dividirse en pretérito y futuro, y el presente no tiene espacio ninguno" 26.

Es este carácter evanescente del tiempo, del presente, el que suscita en el hombre esa añoranza radical, esa nostalgia profunda que circula a través de la poesía, el arte y el saber de todas las épocas. El tiempo no se detiene, no puede detenerse nunca. Fluye constantemente hacia el pasado. $Y$ todos somos náufragos en esa corriente no interrumpida de la temporalidad.

Sobre la sucesión, sin embargo, surge un nuevo aspecto fundamental, aparece el tiempo como duración y como medida. Comparamos entre sí los distintos intervalos de tiempo, y decimos que unos son más largos y otros más breves, y determinamos cuánto sea más largo o más corto aquel tiempo que éste ${ }^{27}$. También ordenamos los movimientos de los cuerpos en el tiempo. Cuánto duró, preguntamos, este o aquel movimiento, o un movimiento, comentamos, es dos veces más largo que otro ${ }^{28}$. El tiempo como medida no puede consistir en ese movimiento de los cuerpos, en el movimiento del sol, de la luna, o de otra realidad determinada ${ }^{29}$. Ciertamente que si nada se moviese no habria tiempo, puesto que en tal caso todo permanecería. Pero el tiempo no se reduce a un movimiento $u$ otro, porque es el tiempo mediante lo que medimos el movimiento, y no el movimiento por lo que medimos el tiempo. De este modo, concluye San Agustín, "si un cuerpo se mueve unas veces más o menos rápidamente y otras está parado, no sólo medimos por el tiempo su movimiento, sino también su quietud, y decimos: "tanto estuvo parado cuanto se movió", o "estuvo parado el doble o el triple de lo que se movió", y cualquier otra cosa que comprenda o estime nuestra dimensión, más o menos, como suele decirse. No es, pues, el tiempo el movimiento de los cuerpos" ${ }^{30}$.

\footnotetext{
26. Cont. $X 1,15,20$, PL 32,817 .

27. Conf. $X I, 16,2$ col. 817 .

28. Conf. $X I, 23,30$ col. 821.

29. Conf. XI, 23, 29, col. 820 .

30. Conf. XI, 24, 31, col. 822 .
} 
El tiempo como medida del movimiento supone el tiempo como duración. Sólo podrá constituirse el tiempo en medida si dura. La medida es una totalidad que actủa como unidad distensa. $\mathrm{Y}$ esta unidad distensa implica una previa y determinada prolongación. De ahi que también el tiempo pueda ser medido por el tiempo. Quiero decir que toda duración puede ser considerada a través de unidades de duración. Pero, ¿qué es lo que dura y qué es esta medida?

Supongamos, considera el Obispo de Hipona, que se trata de medir un verso cualquiera, un verso, por ejemplo, que conste de ocho sílabas, alternando las breves con las largas. Cada una de las largas con respecto a cada una de las breves vale, decimos, doble tiempo. Yo las pronuncio y las repito, y veo oue es así. "Pero cuando suena una después de otra, si la primera es breve y larga la segunda, ¿cómo podré retener la breve y cómo la aplicaré a la larga para ver que la contiene justamente dos veces, siendo asi que la larga no empieza a sonar hasta que no cesa de sonar la breve? Y la misma larga, ¿por ventura la mido presente, siendo así que no la puedo medir sino terminada? $\mathrm{Y}$, sin embargo, su terminación es su preterición. ¿Qué es, pues, lo que mido? ¿Dónde está la breve con que mido? ¿Dónde la larga que mido? Ambas sonaron, volaron, pasaron, ya no son... Luego no son las silabas, oue ya no existen, las que mido, sino mido algo en mi memoria y que permanece en ella fijo" 31. Lo que dura, por lo tanto, es una afección subjetiva producida por la impresión de las cosas fluyentes y retenida mediante la memoria. Sin memoria no hay duración. Por eso la duración no es absoluta, es variable, relativa al sujeto: "un verso breve puede sonar durante más tiempo si se pronuncia más lentamente que otro más largo"... El tiempo como duración es una distensión pero una distensión subjetiva, una distensión animica. (Inde mihi visum est nihil esse aliud tempus quam distentionem. Sed cuius rei, nescio, et mirum, si non ipsius animi) ${ }^{32}$. $\mathrm{Y}$ el tiempo como medida es una unidad racional aplicada a la duración y al movimiento, un artificio para contar el movimiento y la duración, construido sobre la base de la misma duración ${ }^{33}$.

\footnotetext{
31. Conf. $X I, 27,35$, col. 823 .

32. Conf. XI, 26, 33, col. 822

33. Conf. XI, 27; 36 , col. 823-824.
} 
Situados ya en este terreno podemos hablar de futuro, de pasado y de presente. En realidad los tiempos futuros aún no son. Existen en el alma como afección, como proyecto, como expectación. Tampoco el pretérito existe. Se da en el alma como memoria del pretérito. $\mathrm{Y}$ el presente carece de duración por pasar ininterrumpidamente, mas perdura mediante la atención "por donde pasa al no ser lo que es" ${ }^{34}$. Y también existen las cosas pasadas, presentes y futuras. Dondequiera que existan, sin embargo, no son propiamente pretéritas ni futuras, sino presentes. De este modo los tres tiempos se convierten en tres tipos de presencialidad: presente de las cosas pasadas, presente de las cosas presentes, y presente de las futuras. Pero esta presencialidad únicamente se da en el alma como función: "Porque estas son tres cosas, dirá San Agustín, que existen de algún modo en el alma, y fuera de ella yo no veo que existan: presente de las cosas pasadas (la memoria), presente de las cosas presentes (visión), y presente de cosas futuras (expectación) ${ }^{35}$. Con lo cual hemos roto todo esquema absoluto de medida introduciéndonos en un tiempo propiamente psicológico. Veámoslo con algún detenimiento.

\section{PRAESENS DE PRAETERITIS}

El alma es lo que, según hemos visto, proporciona realidad y consistencia al tiempo como duración y al tiempo como medida: In te, anime meus, tempora metior. $\mathrm{Y}$ lo que en el alma hace posible la duración es la memoria: Aliquid in memoria mea metior, quod infixum manet. Pero esta participación de la memoria dota al tiempo de una peculiar dimensión. Lo constituye en cuanto presencialidad. De esta forma los tres modos fundamentales de lo temporal: presente, pasado y futuro, pasan a ser tres tipos de presente, y, por lo tanto, tres aspectos de la memoria, a los que Agustín designa con tres nombres especiales: memoria, contuitus, exspectatio. Estos dos últimos significan funciones anímicas que sólo son posibles en cuanto que la memoria misma se extiende al presente $\mathrm{y}$ al futuro.

En la memoria sensible y en la memoria afectiva pusimos de relieve las condiciones y los modos propios de fija-

34. Conf. XI, 28, 37, col 824.

35. Conf. XI, 20, 26, col. 819 . 
ción y conservación tanto de las impresiones sensibles como de las afecciones subjetivas. No son las cosas mismas ni los sentimientos o apetitos los que se graban $\bar{y}$ conservan en la memoria, sino sus imágenes y nociones. $Y$ esta capacidad del alma amplía, engrandece, aumenta progresivamente el campo de posibilidades humanas, que permitirán un desarrollo más armónico y congruente de la personalidad en todos los sentidos.

La memoria como presencia de cosas pasadas nos ofrece ahora una característica distinta. Lo que mediante ella se retiene, en cuanto adquirido por la experiencia, se reviste en esta nueva perspectiva de la temporalidad. La memoria nos permite situar en el tiempo todo lo que hemos vivido y sentido. Pero esta situación en el tiempo rompe, a su vez, la estructura del tiempo mismo como sucesión y como medida absoluta. Es decir, el tiempo se transforma en duración. De este modo, cuando evocamos una acción pasada la estamos haciendo presente, la hemos salvado del naufragio del pasado, del antes total y de la transitoriedad del momento en que sucedió. Tiramos del pasado hacia el presente y no permitimos que perezca. También el pasado en cuanto conservado se transforma en un presente continuado. Así, mi infancia, "que ya no existe, existe en el tiempo pretérito que tampoco existe; pero yo recuerdo o describo su imagen, en tiempo presente la intuyo, porque existe todavía en mi memoria" ${ }^{36}$.

Admiración, sorpresa y pasmo le produce a San Agustín la capacidad conservadora de la memoria. Cientos, miles de imágenes de cosas, cientos y miles de acontecimientos están allí depositados, almacenados, retenidos. $Y$ todo este mundo es el que hace posible el pasado como realidad, con la única realidad que puede predicarse, atribuirse a las cosas, esto es, con una realidad presente. Sin embargo, afirmar la realidad presente del pasado, como tal pasado, es contradictorio. Porque el pasado, como pasado, ha dejado de existir. Por eso, sólo podrá decirse el presente del pasado, no en sí mismo, sino en algo distinto, en todo aquello que lo conserve. $Y$ fundamentalmente, en consecuencia, en la memoria, ya que es la facultad por excelencia de conservación del pa-

36. Conf. XI, 18, 23, col. 818 . 
sado: "Los que narran cosas pasadas, comenta San Agustín, no narrarán cosas verdaderas, ciertamente, si no viesen aquellas con el alma, las cuales, si fuesen nada, no podrían ser vistas de ningún modo" ${ }^{37}$.

Esta memoria del pasado, por otra parte, no afecta sólo a las cosas en la medida en que son sensiblemente conocidas por el sujeto, sino que afecta al sujeto como cognoscente, al "yo mismo" en toda su amplitud. Lo sentido y el sentir, lo visto y el ver quedan enlazados en el hilo del tiempo, de un tiempo que perdura. Esta es la razón por la que la memoria hace posible el pasado objetivo y el subjetivo, siendo a la vez testimonio de la temporalidad del mundo y de la temporalidad humana. Un pasado largo es una larga memoria del pasado. $Y$ no es que exista el pasado con independencia de la memoria para ser mediante ella fijado y conservado, sino que el pasado mismo sólo existe como función de la memoria, del alma. El carácter de ya experimentadas, sentidas, "habidas", que adquieren nuestras vivencias es un resultado de esa facultad, que permitirá, por otro lado, al hombre disponer constantemente de una gran riqueza espiritual diariamente aumentada y perfeccionada con el paso de los acontecimientos y realidades presentes.

\section{PRAESENS DE FUTURIS}

Más original y aparentemente más paradójica es la presentación de la memoria como presencia o facultad del futuro. San Agustín se esfuerza en revelar el lazo y la unión, mediante la memoria, de nuestro pasado con nuestro futuro. Lo original no consiste aquí en la nota constantemente destacada de que la tela, la base de todos nuestros proyectos para el porvenir, es debida a los recuerdos e imágenes que se han acumulado mediante percepciones anteriores: "De este mismo tesoro - ya hemos citado el texto- salen las semejanzas tan diversas unas de otras, bien experimentadas, bien creídas en virtud de las experimentadas, las cuales, cotejándolas con las pasadas, infiero de ellas acciones futuras, acontecimientos y esperanzas, todo lo cual lo pienso como presente. "Haré esto o aquello", digo entre mí en el

37. Conf. $\mathrm{XI}, 17,22$, col. 818 . 
seno ingente de mi alma, repleto de imágenes de tantas y tan grandes cosas" ${ }^{38}$.

Anticipamos el futuro, tejemos el porvenir con los múltiples hilos de nuestras experiencias pasadas. Si borramos del alma todos los conocimientos adquiridos, todas las nociones conservadas, todas las sensaciones habidas, nos quedamos ciegos ante el futuro, sin posibilidades de relación ante esa impresionante incógnita de lo que todavía no ha llegado a ser.

La significación más profunda de la duración en el hombre es la tensión activa y dinámica hacia el porvenir, y no solamente duración influyente del pasado y posesión del mismo, pasivamente lograda, acumulada en nosotros. La característica de esta duración es la afirmación misma del hecho fundamental que el hombre, en su duración, se proyecta hacia el futuro. Lo cual implica una memoria que es predominantemente expectatio más bien que recordatio ${ }^{39}$ : “¿Quién hay, en efecto, que niegue que los futuros aún no son? $\mathrm{Y}$, sin embargo, existe en el alma la expectación de los futuros... No es, pues, largo el tiempo futuro, que no existe, sino que un futuro largo es una larga expectación del futuro... Supongamos que voy a recitar un canto sabido de mí. Antes de comenzar, mi expectación se extiende a todo él; mas en comenzándole, cuanto voy quitando de ella para el pasado, tanto a su vez se extiende mi memoria y se distiende la vidà de esta mi acción en la memoria, por lo ya dicho, y en la expectación, por lo que he de decir" ${ }^{40}$.

Esta expectación es la que hace de la vida humana un permanente empuje hacia adelante. El hombre está alerta respecto al contorno y puede disparar su acción por estímulos inmediatos, pero puede también prefigurar el futuro y determinar entre sus posibilidades una concreta manteniéndose "expectante" respecto a ella. Es más, el pasado mismo, en cuanto activamente conservado lleva consigo cierta presencia del futuro. La convicción de que el fuego quemó esto o aquello me confirma que también lo quemará si de nuevo vuelven a ponerse en contacto ambas realidades.

\footnotetext{
38. Conf. $X, 8,14$, col 785 .

39. Conf. $X I, 20,26$, col 819 .

40. Conf. XI, 28, 37-38, col. $824-825$.
} 
Podría pensarse que en la interpretación de San Agustín estamos atribuyéndole una confusión entre la memoria y la imaginación, sobre todo con aquellas formas que en términos psicológicos se denominan imaginación planeadora e imaginación creadora. Cierto que la expectación del futuro, la esperanza, se expresan mediante representaciones concretas que van más allá de lo sensiblemente dado, de lo experimentalmente ofrecido. El inventor, el poeta, el artista llegan a plasmar en su obra el futuro. Consiguen representar, apresar a través de la imagen el porvenir. En ocasiones es tan grande la fuerza creadora que logran trasladarnos a un mundo totalmente distinto del inmediato y empírico, pero que ya, desde el primer momento, intuimos que habrá de cumplirse inexorablemente. Estos zambullidos del inventor, del poeta, del artista en el futuro ponen de manifiesto el poder del "genio" que al fin rompe la barrera de lo presente concreto para alcanzar lo permanente y eterno. Pero estas formas representativas que sobrepasan lo realmente dado no pueden explicarse a partir tan sólo de experiencias previas, puesto que, como hemos dicho, las sobrepasan y ni siquiera como conjetura podrian deducirse. Son el resultado de una búsqueda dolorosa, trágica con frecuencia. La vida humana se sacrifica en esa persecución que está más allá de toda medida. $Y$ en ocasiones se nos presenta como resultado de una energía sobrecogedora que calificamos de diabólico o sobrenatural. $\mathrm{Y}$, por el hecho de no poder explicarse precisamente mediante determinadas vivencias anteriores, tenemos que suponer la existencia en el sujeto de un tipo de presencias más radicales y profundas que las meramente conscientes, que las impresiones sensibles y los sentimientos concretos. Tenemos que suponer también la existencia de una facultad donde se den esas presencias, una memoria anterior a toda memoria sensible. Se trata de un modo de la memoria del futuro netamente agustiniano que consiste en ser anticipación de la eternidad y tensión hacia ella, claramente expresada, por ejemplo, en la tendencia a la "vida bienaventurada".

Todos los hombres desean ser felices, y todos, sépanlo o no, "poseen de algún modo dentro de sí mismos la vida bienaventurada": "¿Pero, acaso no es la vida bienaventurada la que todos apetecen, sin que haya ninguno que no la 
desee? Pues ¿dónde la conocieron para así quererla? ¿Dónde la vieron para amarla? Ciertamente que tenemos su imagen no sé de qué modo. Mas es diverso el modo de serlo el que es feliz por poseer realmente aquella y los que son felices en esperanza. Sin duda que éstos la poseen de modo inferior a aquellos que son felices en realidad; con todo, son mejores que aquellos otros que ni en realidad ni en esperanza son felices; los cuales, sin embargo, no desearan tanto ser felices si no la poseyeran de algún modo; y que lo desean es certísimo... y si pudiesen ser interrogados "si querían ser felices", todos a una responderían sin vacilación que querian serlo. Lo cual no podrían si la cosa misma, cuyo nombre es éste, no estuviese en su memoria" ${ }^{41}$.

El hombre apunta constitutiva y ontológicamente al futuro en el que trata no sólo de realizarse, sino de realizarse felizmente. Lo que pretende y busca es ser féliz. $Y$ no apetecería una cosa tal si no la poseyese de algún modo dentro de sí. Este barrunto de la vida féliz únicamente puede arrastrar al hombre cuando de alguna manera está ligado al modo exclusivo de serlo, que es el serlo permanentemente.

Por eso, como ha escrito Sciacca comentando a San Agustín, el verdadero futuro del espíritu no es el estar abocado a la muerte. El verdadero fin de la vida no es su propio fin, sino el transcender su fin temporal en el fin extratemporal... No se trata de negar el tiempo en la eternidad, o la eternidad en el tiempo. Se trata de la participación del tiempo en la eternidad ${ }^{42}$.

\section{PRAESENS DE PRAESENTIBUS}

Escribió Unamuno que "la realidad no es más que un esfuerzo del recuerdo por hacerse esperanza, o un esfuerzo de la esperanza por convertirse en recuerdo" ${ }^{43}$.

Esta frase desprendida de su propio contexto adquiere un sentido profundo en la doctrina agustiniana de la memoria. El recuerdo no es, para San Agustín solamente re-

\footnotetext{
41. Conf. X, 20, 29, col. 792 .

42. SCIACCA, M. F.: II conceto de storia in S. Agostino, "San Agustin". Est.

y Col., Zaragoza, 1960, p. 22.

43. UNAMUNO, Miguel de: Viejos y Jóvenes, Ed. Espasa Calpe, Madrid, 1959.
} 
cuerdo vital o existencial, no es sólo memoria del pasado propio, de experiencia, sino, y radicalmente, memoria del presente anímico, y memoria del futuro hacia el que apuntan todas las esperanzas. En este sentido, la esperanza, que surge de aquella fuerza hacia adelante que brota en la raíz misma de la memoria, tira del futuro hacia el presente para llegar a realizarse y constituir de este modo el plano existencial del hombre, que, a su vez, terminará convirtiéndose en recuerdo de hechos y recuerdo para la posteridad en donde pueden cumplirse los anhelos del ser humano.

La realidad, el presente, es la línea de incidencia del pasado y del futuro. Pero este presente mismo, en el que futuro $y$ pasado desembocan, adquiere, como forma independiente de la temporalidad, una dimensión propia. $Y$ también esta dimensión se hace posible por la intervención de la memoria.

La memoria es, por lo tanto, la facultad de la duración en toda su riqueza y amplitud. Es la facultad del pasado, del futuro y del presente.

Supongamos, por ejemplo, que se trata de determinar el tiempo, la duración, de una voz que empieza a sonar, continúa sonando, y luego cesa, se hace silencio. Cuando se hace el silencio, aquella voz ha pasado a ser pretérita. Ha dejado de existir. Antes de comenzar a sonar era futura. No era todavía. Por consiguiente, en ninguno de los dos casos podía ser temporalmente medida. Sólo mientras suena puede ser de este modo determinada. Pero mientras suena no ha alcanzado todavía su fin. $Y$ si no ha alcanzado su fin, no podemos decir lo que efectivamente duró, porque aún dura. $Y$ cuando llegue a su fin, el comienzo habrá cesado. No es, pues, la voz misma lo que medimos, sino la afección subjetiva que produce al sonar y que es en la memoria conservada. Es decir, la memoria es lo que propiamente hace posible la duración. $Y$ sin la memoria de ninguna cosa afirmaríamos una duración más o menos larga, ya que es ella la que la hace efectiva ${ }^{44}$.

Esta memoria, síntesis de lo temporal y principio de la temporalización es, por otra parte, condición fundamental de la conciencia. No se pretende defender que la memoria

44. Conf. XI, 27, 35, PL $32,823$. 
sea la conciencia, sino, simplemente, que la conciencia como autopresencia o heteropresencia es imposible sin la memoria. En primer lugar, porque toda presencia en tanto es presencia en cuanto es durable, en cuanto rompe y detiene el desmenuzamiento de la sucesión. Y esta retención de lo sucesivo sólo se efectúa mediante la memoria. En segundo lugar, porque la primera forma de presencia, aquella en la que el dato se configura en una cierta totalidad, o simplemente se mantiene para una ulterior relación, sólo puede tener también lugar en la memoria. En un momento posterior ese dato, o esta totalidad, se revestirán de las funciones de la conciencia que se caracterizan, desde el punto de vista psicológico, como un "darse cuenta", un "percatarse" de lo que está ahí, de lo que ha sido dado, de lo que está presente. Pero no se puede olvidar que el "darse cuenta" supone previamente la presencia misma, es decir, la memoria. De lo contrario tendríamos un "darse cuenta" que sería un "darse cuenta" de nada, esto es, un "no darse cuenta". Por eso San Agustín define en primer lugar la memoria como la facultad del presente, de lo que está presente, o del estar presente, que es lo mismo ${ }^{45}$.

La memoria une el pasado y el porvenir en un presente que se desplaza sin cesar. Y la memoria es, al mismo tiempo, toda duración presente por dilatada que se la suponga: día presente, mes presente, año presente, hasta el momento en que abarque toda nuestra vida presente, o toda historia presente ${ }^{46}$.

Es como si el hombre estuviese siempre en peligṛo de naufragar en la negación del pasado o del futuro, salvándose de este hundimiento por esa virtud de la memoria capaz de actualizarlos y hacerlos presentes. En traerlos hacia sí y conservarlos se esfuerza el poder de esta facultad nuestra para "ser" y "tener" lo que estamos siendo, o lo que hemos sido, o lo que queremos ser.

En la diversidad y en la unidad de esta memoria ha encontrado Agustín, por otra parte y como varias veces se ha dicho, la división y centro de sus Confesiones. Estas son evocación del pasado, de la dialéctica pausada que ha hecho nacer $\mathrm{y}$ crecer en él el sentimiento de responsabilidad, que

\footnotetext{
45. Conf. XI, 20, 26, col. 819 .

46. Conf. XI, 15, 19 ss, col. 816-817.
} 
le ha conducido en su reflexión explícita, del racionalismo a la fe. Ellas son, a continuación, la expresión del presente, de la presencia de Dios en esta memoria que poco a poco va aproximándose a la conciencia. Son, finalmente, anticipación del futuro en su tensión a la eternidad que será la revelación del Dios que enseñan las Escrituras cuya esperanza transfigura ya el mundo en un símbolo, en un sacramento de la vida futura.

Agustín siente un estremecimiento religioso al adentrarse en el examen minucioso de la memoria ${ }^{47}$. Este estremecimiento es una preparación para penetrar en un plano anterior a la conciencia, al descubrimiento en el fondo del espíritu de una presencia que escapa al pensamiento explícito, que resiste a los esfuerzos de la objetivación.

Tanto la duración como la presencia llevan consigo, sin duda ninguna, cierta diversidad de grados. La duración sensible comporta, desde luego, una presencia. Pero es una presencia que huye a medida que los instantes se desplazan. Es ausencia tanto como presencia. La función reproductora dura también: $Y$ t's susceptible, en un momento superior, de ser temporalmente reproducida. Pero tiene unos límites muy precisos a medida que la vida avanza. Agustín, sin embargo, ya desde los primeros pasos por el campo del pensamiento, presiente en la memoria la huella de lo abstracto, la presencia de lo eterno, que será lo que la constituya verdaderamente en memoria espiritual. $Y$ todo su esfuerzo va encaminado a descifrar este misterio. La verdad, el Ser, lo eterno se irán desvelando en lo más recóndito de la memoria. Esta facultad irá adquiriendo así categoria metafísica.

\section{MEMORIA Y PERSONALIDAD}

Otra de las características de la memoria en San Agustín consiste en presentárnosla como personal y fundamento de la personalidad. Frente al carácter pático de bastantes actuaciones del hombre, en las que más que protagonista se siente protagonizado, destaca el yo como centro de energía $\mathrm{y}$ punto de arranque del comportamiento. El yo surge y

47. Conf. $X, 8,15$, col 785 . 
se manifiesta, precisamente, en el momento en que se presenta como fuente de actividad. En las tendencias básicas, inclinaciones, apetitos, instintos, el hombre es arrastrado, impulsado, movido. Con el yo, el hombre mueve, impulsa y arrastra. $\mathrm{Y}$ a este yo energético, anímico, espiritual pertenece la memoria como actividad. Magna vis est memoriae... et hoc animus est, et hoc ego ipse sum ${ }^{48}$. Ego sum qui memini, ego animus ${ }^{49}$.

Pero esta función del yo permite, por otra parte, la identificación consigo mismo y la perduración más allá del aquí y el ahora concreto de cada vivencia. No es posible ser uno mismo a lo largo de los años de existencia, si no es por la capacidad de esta facultad que nos permite reconocer el pasado como nuestro pasado y el presente como nuestro presente: "Allí, (en la memoria), me encuentro con mí mismo y me acuerdo de mí y de lo que hice, y en qué tiempo y en qué lugar, y de qué modo y cómo estaba afectado cuando 10 hacia"-Ibi mihi et ipse occurro meque recolo- ${ }^{50}$.

Este encuentro y reconocimiento de sí es la raíz y el fundamento de la personalidad. La organización de los propios actos saltaría rota en mil intentos fallidos a no ser por esta propia pervivencia. La continuidad del pensamiento, la conexión de los recuerdos es, de este modo, la condición de la personalidad no sólo en su carácter histórico, sino también en su aspecto sensible e intelectual. Quizá por estas razones llegó a considerar Wolff la persona como el ente que conserva la memoria de sí, esto es, que recuerda ser lo mismo que fue precedentemente en este o aquel estado. San Agustín, indudablemente, no reduce la persona ni la personalidad a recuerdo. Encuentra únicamente en la memoria una condición esencial. Lo que sí podríamos afirmar, dentro de la doctrina agustiniana, es que la memoria proporciona el tema, la meta de la personalidad, en cuanto que la personalidad es la realización íntima, armónica y organizada de la persona y sólo puede llevarse a cabo desde el íntimo descubrimiento de lo que el hombre debe ser.

También en los animales tiene, de cierta manera, aplicación la capacidad unitaria de la memoria. Porque, efectiva-

\footnotetext{
48. Conf. $X, 17,26$, col. 790 .

49. Conf. $X, 16,25$, col. 789 .

50. Conf. $X, 8,14$, col. 785 .
} 
mente, los animales tienen memoria: "Las bestias y las aves tienen memoria, puesto que de otro modo no volverían a sus madrigueras y nidos, ni harian otras muchas cosas a las que se acostumbran, pues ni aun acostumbrarse pudieran a ninguna si no fuera por la memoria" ${ }^{51}$.

"No le basta al animal el puro instinto de conservación o apetito de unidad para conservar su ser unitario, ya que el animal es algo más que la materia y entra ya en la categoría de la vida. No sólo tiene que defenderse de la amenaza de la destrucción, sino que necesita ser él mismo, es decir, superar esa discontinuidad que de por sí impondría la fragmentación temporal de su vida".

Tratándose del hombre, sin embargo, el asunto reviste de pronto una capital importancia. Sobre todo, porque en el hombre falla el sistema de los instintos más profundamente que en el animal y porque el "hacerse", el "hacerse libremente", es en él tarea esencial e ineludible.

Cuando Lain Entralgo trata de representar la vida de un hombre mediante lo que él llama "curva vital", afirma: "si este curso está parcialmente determinado por la complexión psicosomática de la persona (enfermedades y limitaciones orgánicas, sean hereditarias o adquiridas) y por las condiciones del medio en que esa persona vivió (en su triple aspecto de campo cósmico, ambiente biológico y mundo histórico-social), en parte —en su parte esencial- está libremente elegido y decidido por el biografiado. Por lo tanto la curva representa también la expresión visible de lo que un hombre quiso hacer de su vida, el rostro temporal de su personal intimidad. La curva, con su singular e irrepetible trazado, es para cada persona la línea en que se configura temporalmente un permanente compromiso: el compromiso entre la libre intencionalidad de su mundo íntimo y las exigencias, las resistencias o las presiones de su medio" 52 .

Traduciendo esto en términos agustinianos tendríamos que la "curva vital" no interesa tanto por su "configuración temporal", y en cierto modo externa, cuanto por su íntima

51. Conf. X, 17, 26, col. 790 .

52. LaIN ENTRAlgo, P.: Menéndez Pelayo, Madrid, 1944, p. 29-30. 
proyección, aún a parte de su ineludible compromiso externo. Lo que importa es lo que, en definitiva, tiene de íntimo. Pero esta intimidad no podrá nunca desarrollarse plenamente sin el auxilio de la memoria que es la que hace posible una constante referencia al yo capaz de una duración espiritual, y la que nos puede proporcionar la meta de lo que debemos ser.

$\mathrm{Y}$ en este yo que dura espiritualmente, en la conciencia que constituye $\mathrm{y}$ va formando la personalidad de cada individuo se funda y se basa también el arrepentimiento que vemos expresado en tan patéticas frases en todas las obras de San Agustín, sobre todo en sus memorables Confesiones.

\section{DURACION Y PESAR}

Quizá alguien pueda pensar todavía en San Agustín como filósofo de la eternidad abstracta. No faltan en él, desde luego, ciertos indicios que puedan dar lugar a pensar así. Sobre todo, cuando habla de las razones eternas y de la captación de las esencias de las cosas de una manera puramente intemporal. Para San Agustín, sin embargo, la duración espiritual tiene una dimensión muy distinta de todo lo que pueda referirse a pura abstracción o consideración intemporal. Ella es quien explica, por ejemplo, la profundidad y fecundidad del arrepentimiento.

Al considerar los actos humanos no aislados, alejados, terminados de una vez sin ulterior repercusión, sino como partes de un todo al que de una manera $u$ otra realizan, la persona humana adquiere un tono distinto $\mathrm{y}$ se hace responsable por siempre de lo que entonces hizo, al mismo tiempo que es capaz de una transformación organizada en cada acto hacia una mayor perfección.

"El considerar las acciones de los hombres - ha escrito el P. A. C. Vega - como partes de una vida integral del individuo, es una de las ideas más geniales y fecundas de San Agustín, que desarrolla admirablemente en su Ciudad de Dios. Al hablar de la filosofía de la historia es frecuente, por no decir exclusivo, considerar la Providencia Divina como el elemento principal de aquella, cuando en realidad semejante 
pensamiento es común a todos los escritores cristianos. Pero considerar la humanidad como un hombre, como una sola vida, que se desarrolla a través de los siglos bajo la égida divina, transmitiendo unos pueblos a otros la antorcha de la civilización y desapareciendo lo imperfecto para dar lugar al desarrollo de un nuevo organismo, esto, digo, se halla por vez primera en San Agustín, para quien no hay más que una historia, una cultura" ${ }^{53}$.

Lo importante, en este caso, es señalar la unidad vital del individuo, únicamente posible por la acción de la memoria: "Supongamos que voy a recitar un canto sabido de mí. Antes de comenzar, mi expectación se extiende a todo él; más en comenzándole cuanto voy quitando de ella para el pasado, tanto a su vez se extiende mi memoria y se distiende de la vida de esta mi acción en la memoria, por lo ya dicho, y en la expectación, por lo que he de decir. Sin embargo, mi atención es presente, y por ella pasa lo que era futuro para hacerse pretérito. Lo cual, cuanto más y más se verifica, tanto más, abreviada la expectación, se alarga la memoria, hasta que se consume toda la expectación, cuando, terminada toda aquella acción, pasare a la memoria.

Y lo que sucede con el canto entero, acontece con cada una de sus partecillas y con cada una de sus sílabas; y esto mismo es lo que sucede con una acción más larga, de la que tal vez es una parte aquel canto; esto lo que acontece con la vida total del hombre, de la que forman parte cada una de las acciones del mismo; y esto lo que ocurre con la vida de la humanidad, de la que son partes las vidas de todos los hombres" 54

La idea es de una fecundidad asombrosa. Cada una de nuestras acciones, por insignificantes, por diminutas que sean, representan en el conjunto total de nuestras vidas algo parecido a lo que supone la nota más leve, más débil, en la realización de una sinfonía musical. Toda la fuerza del futuro y todo el peso del pasado gravitan sobre su pequeña osamenta. El futuro está conquistado, la expectación cumplida, y el pasado recuperado. $\mathrm{Y}$ todavía adquiere esto un sentido más ra-

\footnotetext{
53. VEGA, P.A.C.: Nota 44 al 1. XI de las Confesiones, BAC, Madrid, 1951, p. 603.

54. Conf. XI. 28, 38, PL 32, 824-825.
} 
dical en el pensamiento de San Agustín. Porque la sinfonía musical que interpreto, como la vida que realizo, ya es de alguna manera sabida por mi, aunque sólo vaya expresándose a través del paulatino desarrollo del presente. El conocimiento no será total, no estará completo, hasta que no sea totalmente expresado. Pero ya antes de ser expresado es en cierto modo conocimiento. Por eso, cada acto, cada nota, tiene una capital importancia, aún sabiendo que su sentido último vendrá dado con la última expresión. Si cualquiera de estos actos desapareciese, la vida quedaría interrumpida y la sinfonía rota. A su vez cada acto, cada nota, debe ser continuado, —no en él mismo, sino en otros distintos-, hasta el final, ya que sólo al final conseguirá su pleno sentido.

Por otra parte, cuando el acto pertenece a una vida, a una vida personal, no ha pasado enteramente, ni jamás será acabąo y consumado totalmente: sus consecuencias no se extinguen, sus resultados permanecen incluso dentro de una transformación total.

"El acto, se ha dicho, se cumple y pasa. Si yo mato a un hombre, le mato de una vez, no le estoy matando siempre; la historia de mi homicidio tiene un comienzo y una terminación. Pero ¿de verdad tiene una terminación? Si en vez de considerar el acto recortado considero ahora la posibilidad que he realizado, hay que contestar negativamente. Soy ya, de una vez para siempre, homicida. Incluso aunque me arrepienta, mi acción se conservará siempre bajo la forma de "haber matado" ${ }^{55}$.

Es decir, al realizar esa posibilidad de mi vida en lugar de otra cualquiera de las muchas que en ese momento se me ofrecian me he convertido por siempre en un ser que efectivamente realizó aquella posibilidad. La explicación que podemos deducir de la doctrina agustiniana introduce una variante en este sentido. El pasado no ha pasado totalmente porque pertenece a una vida personal, intransferible y única, a una vida que, por otra parte, es "distensión" ${ }^{56}$, a una vida que "dura". Cada experiencia de nuestra vida pasada permanece, por lo mismo, indeterminada en cuanto al sentido último e incompleta en cuanto al valor, ya que no ha podi-

55. ARAnguren, J. L.: Etica, Rev. de Occ., Madrid, 1959, p. 77-78.

56. Conf. XI, 29, 39, PL $32,825$. 
do producir todos los efectos posibles. Nuestro pasado, pasado de seres inteligentes y libres, de seres espirituales, nos ofrece, con tal que aceptemos la acusación y pesar de nuestros yerros, no un dato definitivo, sino un dato de un problema al cual podemos dar aquí y hasta la muerte una expresión nueva. Somos un todo orgánico que se desarrolla a 10 largo de toda nuestra existencia, y que, por lo tanto, sólo obtendrá su significado definitivo al final.

No estamos tratando aquí de un tiempo físico, cósmico, donde los eventos son dispuestos siguiendo una línea y desaparecen tan pronto como son presentados. Tratamos, por el contrario, del tiempo en que vivimos nuestra duración íntima y personal. Por eso, aunque interpretados por el pasado, no permanecemos a él totalmente adscritos. $\mathrm{Y}$ por eso también nuestro pesar y arrepentimiento serán siempre posibles. Porque el pesar y el arrepentimiento son, a la postre, un cambio en la dirección de la vida mediante el cual vamos expresando lo que somos y lo que queremos ser.

\section{DURACION Y CONOCIMIENTO}

Se ha considerado a veces los actos del espíritu: percepciones, juicios, razonamientos como entidades abstractas. La concepción, empero, de la memoria como duración nos permite dar a estos actos un sentido distinto, nos permite temporalizarlos y espaciarlos, nos permite considerarlos como acciones que se hacen, que se desarrollan y se suceden en el tiempo y en el espacio de algún modo. Estos actos son, como declara San Agustín en el De Musica, sintesis en el tiempo ${ }^{57}$.

Es, efectivamente, evidente que para emitir un juicio simplemente, o simplemente pensar, es preciso tener presente el sujeto al tiempo que se va a enunciar el predicado. La duración es la condición primordial de toda operación de conciencia. Gracias a esta duración, a la memoria, llegan a ser conscientes las operaciones mediante la concentración temporal en uno de lo diverso que el espacio mantendría siendo diverso.

57. De Mus. VI, 8, 21, PL 32, 1174-1175. 
La labor sintética, resultado de la duración, fruto de la memoria, comienza ya en los hechos de conocimiento más elementales. Hoy, la psicología reconoce la duración como una propiedad de las sensaciones y de las percepciones. Pero se resiste a extraer las últimas consecuencias. Lo mismo ocurre en la "teoría del conocimiento". El paso que San Agustín ha dado, percatándose plenamente de su significado, consiste en afirmar desde el primer momento que admitir la duración como propiedad de las sensaciones y de las percepciones es admitir la participación activa del sujeto en los actos sensitivos y perceptivos.

No debemos perder de vista que estamos todavia en el plano sensible, que no hemos llegado al inteligible, desde donde todas estas cuestiones adquieren su máxima fecundidad.

Cuando oímos, pongamos por caso, una palabra, a no ser que formemos inmediatamente una imagen del primer sonido emitido, y esta imagen sea retenida en la memoria, será imposible llegar a tener una percepción de la palabra completa. Ignoraríamos si una sílaba era la segunda, o la tercera, porque las sílabas irían totalmente desapareciendo al ser pronunciadas. La palabra como una totalidad significativa sería imposible. El lenguaje, la música, los movimientos tan distintos de los cuerpos irian desvaneciéndose a medida que fuesen pasando y el espíritu saltaría destruido ante los impactos de los múltiples estímulos de cada instante. Sólo la memoria, que los va reteniendo, hace posible su captación y el progreso en torno a los objetos sensibles. Pero además, a los datos sensibles, conservados en sus imágenes, se anticipan las imágenes de datos futuros. De este modo completamos las palabras que se pronuncian incompletas en la conversación, o frases sin terminar, que se interrumpen an. tes de ser totalmente dichas y que nosotros creemos oír integras. Nuestros actos son, así, anticipados en parte por el espíritu, siendo la percepción actual el resultado y síntesis de lo conservado en la memoria, de lo anticipado por el alma también en la memoria y de la imagen de lo presente del mismo modo inmediatamente mantenida en la memoria ${ }^{58}$. 
Idéntico problema nos encontramos con la visión de cuerpos que tienen una cierta extensión. Necesitamos recorrerlos con la mirada para hacérnoslos presentes en su conjunto. Pero esto significa que a medida que vamos moviendo la vista de un lugar a otro hemos de ir conservando en la memoria las imágenes de los distintos parajes para conseguir perfilar el paisaje completo. $Y$ si un cuerpo es cuadrado, o redondo, no podemos sentirlo como tal, juzgar la perfección de su figura a no ser que lo hagamos girar para ir viéndolo en sus partes. $Y$ en este caso ya necesitamos recurrir a la memoria para que retenga en imagen lo visto y sea posible completarlo con lo que estamos viendo. De no ser por su intervención, tan pronto como media algún intervalo de tiempo entre las distintas sensaciones, resulta ya imposible atribuirlas a un mismo objeto, y resultarán también imposibles los juicios sobre él ${ }^{59}$.

También necesitamos la memoria en las distintas funciones representativas que constantemente se suceden en el espíritu para obtener mediante ella la medida de su alcance y la corrección de su verificación. Cuando alguien nos narra algo extraordinario parece que participamos en lo que se nos cuenta únicamente mediante la imaginación. Las palabras, a medida que son pronunciadas, suscitan en nosotros un tropel de imágenes que se van sucediendo al ritmo de los vocablos. Pero si lo consideramos atentamente, tampoco aqui hemos prescindido de la memoria. Porque ninguna frase podría ser entendida si no recordásemos el sentido que como tal frase tiene y el de cada una de las palabras de que consta. La memoria nos proporciona la medida exacta de lo que oímos y de lo que debemos entender. "Asi, pues, todo el que piensa en los objetos corpóreos, ya se los imagine, ya los escuche, ya lea sucesos pretéritos, o vaticinios del porvenir, ha de recurrir a la memoria y allí encontrará la medida y el modo de cuantas formas su pensamiento contempla" ${ }^{60}$.

El reconocimiento de las cosas sensibles, de nuestros actos, de los acontecimientos que vayan sobreviniendo, pende, en definitiva, de la aplicación de la memoria. $Y$ si en el pen-

59. De Mus. VI, 8, 21, PL 32, 1174-1175.

60. De Trinit. XI, 8, 14, PL 42, 995 . 
samiento de cosas se produce una escisión, esta escisión ha sido antes pérdida de la memoria. Acompaña al hombre para que toda su vida y lo que le rodea pueda ser clarificado en la conciencia. Querer apartar la mirada del alma del recuerdo equivale a suprimir el pensamiento. Iam porro ab eo quod in memoria est, animi aciem velle avertere, nihil est aliud quam non inde cogitare ${ }^{61}$.

Todo lo que implica movimiento, cambio, sucesión, todo lo que se transforma, deviene, fluye, es decir, el mundo en su constante desplazamiento, la vida con su diario palpitar, necesita de esta facultad para durar y para ser representado, imaginado, pensado. Los datos sensibles, las impresiones, los estímulos, han de llegar hasta el "amplio campo" de su acción para desde allí fructificar en verdadero conocimiento. Sólo así el hombre irá despegándose del momento en que vive, del segundo concreto en que existe, e irá conquistando el puesto extraordinario que en el universo le corresponde.

Por debajo de esta memoria sensible existe una memoria más profunda, una memoria inteligible. Es la memoria en la que habita propiamente la verdad..

La verdad es algo a lo que todos los hombres tienden. $\mathrm{Y}$ esta verdad a la que todos los hombres tienden es también común a todos, no privativa de alguno. Superior a todos. Inmutable. No disminuye, ni aumenta, ni cambia o se transforma. Pero la búsqueda, el deseo de verdad supone el conocimiento de esta misma verdad. Conocimiento que no puede ser sensible, corporal, experiencial, sino puramente mental, y que consiste, fundamentalmente, en la presencia de la verdad en la memoria. Presencia implícita, confusa, oscura, que poco a poco puede ir esclareciéndose en la conciencia, sin que por ello llegue nunca a reducirse a un dato subjetivo, porque es esencialmente superior al sujeto.

Del mismo modo razona San Agustín con respecto a la unidad, a la Sabiduría y sus razones y leyes básicas, a las normas generales del comportamiento humano y las virtudes...

61. De Trinit. $\mathrm{XI}, 8,15, \mathrm{PL} 42,996$. 
El hombre está inmerso en el mundo de lo absoluto, permanente y eterno. La sabiduría humana es sabiduría participada. A imagen de Dios ha sido hecha el alma. Por eso el alma puede acordarse de Dios. De este modo la memoria adquiere una fundamentación metafísica y una dimensión teológica indudable. $Y$ de este modo también la memoria se convierte en centro, punto de incidencia, de lo eterno y de lo temporal, de lo absoluto y de 10 relativo, de lo inteligible y de lo sensible.

Oviedo

Teófilo Rodríguez Neira 